\title{
Periostin has a protective role in melatonin-induced cell apoptosis by inhibiting the eIF2 $\alpha$-ATF4 pathway in human osteoblasts
}

\author{
XIAOTONG MENG, YUE ZHU, LIN TAO, SICHAO ZHAO and SHUI QIU \\ Department of Orthopaedics, The First Affiliated Hospital of China Medical University, Shenyang, Liaoning 110001, P.R. China
}

Received July 13, 2017; Accepted November 28, 2017

DOI: 10.3892/ijmm.2017.3300

\begin{abstract}
The present study aimed to investigate the role of periostin (POSTN) and high melatonin concentrations in the apoptosis of hFOB 1.19 human normal fetal osteoblastic cells. hFOB 1.19 human osteoblastic cells were stably cultured and treated in different concentrations of melatonin for different durations of action. Apoptosis was assessed quantitatively using flow cytometric analysis. The results of western blot analysis demonstrated that the treatment of cells with different concentrations of melatonin for different durations of action revealed a positive association between melatonin and the expression levels of glucose-regulated protein (GRP)78, GRP94, phosphorylated (p-) eukaryotic initiation factor $2 \alpha$ (eIF2 $\alpha$ ), activating transcription factor (ATF)4, CCAAT/enhanced binding protein homologous protein (CHOP), cleaved caspase-3, p-c-Jun N-terminal kinase (JNK) and POSTN. When POSTN was inhibited, the levels of p-JNK, CHOP, p-eIF2 $\alpha$, ATF4 and cleaved caspase-3 were significantly increased, whereas other proteins associated with the endoplasmic reticulum stress (ERS) pathways, including ATF6 and X-box binding protein 1 (XBP1), were not significantly altered. Reverse transcription-quantitative polymerase chain reaction analysis was also performed to assess the relative mRNA levels of ATF4, ATF6 and XBP1. The results of the present study are the first, to the best of our knowledge, to demonstrate that melatonin induced apoptosis in hFOB 1.19 human osteoblastic cells by activating the ERS-associated eIF2 $\alpha$-ATF4 pathway and subsequently triggered the cascade effects of CHOP, caspase-3 and JNK. POSTN may function as a protective factor for osteoblasts during this process by inhibiting the eIF2 $\alpha$-ATF4 pathway.
\end{abstract}

Correspondence to: Dr Yue Zhu, Department of Orthopaedics, The First Affiliated Hospital of China Medical University, 155 Nan Jing Bei Street, Shenyang, Liaoning 110001, P.R. China E-mail: zhuyuedr@163.com

Key words: melatonin, periostin, apoptosis, eukaryotic initiation factor $2 \alpha$-activating transcription factor 4 pathway, CCAAT/enhancer binding protein homologous protein, caspase- 3

\section{Introduction}

The pineal gland is the most important producer of melatonin. In 1959, Thillard (1) demonstrated that pinealectomy in a chicken enabled construction of a model of spinal deformity, and the association between melatonin and spinal deformities has received considerable attention since. It is well known that spinal deformity is often caused by the abnormal proliferation of osteoblasts initially. It has been confirmed that osteoblast proliferation is dependent on the concentration of melatonin and the mechanism has been verified $(2,3)$. However, the ability of melatonin to cause osteoblast apoptosis (plus the underlying molecular mechanisms), and any potential protective factors is may possess remains unclear.

Previous studies have demonstrated that there is a potential connection between melatonin, endoplasmic reticulum stress (ERS) and apoptosis. Furthermore, previous results have indicated that melatonin is able to promote apoptosis $(4,5)$; however, other studies have suggested that melatonin is able to inhibit ERS and/or apoptosis $(6,7)$. The traditional form of apoptosis is known as the caspase-dependent pathway, consisting of the death receptor pathway and the mitochondria-mediated pathway (8-10). Cell apoptosis may be induced through the activation of caspase-3, which triggers the caspase cascade (11). ERS is able to induce apoptosis through the unfolded protein response (UPR), the ER overload response and the sterol cascade (12-14). The UPR signal transduction pathway is the most frequently used, and is mediated by three transmembrane proteins involved in three signal transduction pathways; protein kinase R-like endoplasmic reticulum kinase (PERK) pathway, the inositol-requiring enzyme 1 (IRE1) pathway and the activating transcription factor (ATF) $6 \alpha$ pathway $(13,15-17)$. CCAAT/enhanced binding protein homologous protein (CHOP) is an important downstream target of ATF4, which is necessary in the ERS-induced apoptotic response $(18,19)$. c-Jun N-terminal kinase (JNK) activates the death receptor pathway (20) (the JNK mediators belong to the death receptor pathway). Collectively, these three pathways induce apoptosis by activating or inhibiting different factors, including TNF receptor-associated factor 2 , apoptosis signal-regulating kinase 1 and B-cell lymphoma 2 (Bcl-2) $(21,22)$.

Periostin (POSTN) is a secreted extracellular matrix protein, which was originally identified in cells of the mesenchymal lineage, including osteoblasts, osteoblast-derived cells, the periodontal ligament and periosteum. POSTN has been 
associated with the epithelial-mesenchymal transition (EMT) in cancer and also the differentiation of the mesenchyme in the developing heart (23). This protein belongs to the fasciclin I family and is expressed in connective tissues, including the bone, skin, periodontal ligament and tendon. In several types of cancer, POSTN can activate the protein kinase B (Akt) and focal adhesion kinase-mediated signaling pathways, leading to cell invasion, angiogenesis, metastasis and the EMT (24). A previous study also demonstrated that POSTN is expressed by osteoblasts and osteoclasts (25).

Whether melatonin can induce or inhibit apoptosis in the hFOB 1.19 human osteoblastic cell line through specific pathways, and the role of POSTN in osteoblast apoptosis remains unclear. Therefore the present study investigated the role of periostin (POSTN) and high melatonin concentrations in the apoptosis of hFOB 1.19 human normal fetal osteoblastic cells in order to provide further clarification.

\section{Materials and methods}

Cell culture and reagents. The hFOB 1.19 normal human fetal osteoblastic cell line was provided by the Department of Biochemistry and Molecular Biology, Mayo Clinic (Rochester, MN, USA) (26) and was maintained in a 1:1 mixture of Dulbecco's minimum essential (DME) and F12 medium without phenol red (HyClone, Laboratories; GE Healthcare Life Sciences, Logan, UT, USA), supplemented with $10 \%$ fetal bovine serum (FBS) and grown in $5 \% \mathrm{CO}_{2}$ at $37^{\circ} \mathrm{C}$. The medium was replaced every other day. Cells that were passaged 8-11 times were used for all experiments. Treatments with melatonin $(2,4$ or $6 \mathrm{mM})$ dissolved in $0.2 \%$ dimethyl sulfoxide (DMSO) or vehicle treatment with $0.2 \%$ DMSO (in culture medium) were performed at $37^{\circ} \mathrm{C}$ with $10 \% \mathrm{FBS}$.

Melatonin was obtained from Sigma-Aldrich; Merck KGaA (Darmstadt, Germany). Lipofectamine ${ }^{\circledR} 2000$ was purchased from Invitrogen; Thermo Fisher Scientific, Inc. (Waltham, MA, USA). Primary monoclonal/polyclonal antibodies against the indicated proteins were purchased from Abcam (Cambridge, MA, USA). Goat anti-rabbit secondary antibodies were obtained from Zhongshan Jinqiao Biotechnology Co., Ltd. (Beijing, China).

POSTN small interfering (si)RNA transfection. Cells were cultured in DME and F12 medium supplemented with $10 \%$ FBS (Clarks Bioscience, Seabrook, MD, USA) in a humidified incubator at $37^{\circ} \mathrm{C}$ and $5 \% \mathrm{CO}_{2}$. At $70-80 \%$ confluence, cells were transfected with POSTN small interfering (si)RNA (sense, 5'-GGAUCUAGAAGACGAUUAAGG-3'; antisense, 5'-UUA AUCGUCUUCUAGAUCCUU-3'; Shanghai GeneChem Co., Ltd., Shanghai, China) using Lipofectamine ${ }^{\circledR} 2000$ according to the manufacturer's protocol (Invitrogen; Thermo Fisher Scientific, Inc.). Overall, there were 3 control groups: Blank control, transfection reagent control and scramble siRNA control.

Annexin V-fluorescein isothiocyanate (FITC)/propidium iodide (PI) staining and flow cytometric analysis. An Annexin V FITC/PI staining kit was used to assess apoptotic cell death according to manufacturer's protocol (Dojindo Molecular Technologies, Inc., Kumamoto, Japan). Briefly, the cells were trypsinised, washed in PBS, resuspended in binding buffer, stained with FITC-conjugated Annexin V and PI, analysed using the BD LSRFortessa ${ }^{\mathrm{TM}}$ cell analyzer (BD Biosciences, Franklin Lakes, NJ, USA) and evaluated using BD FACSDiva (version 6.2; BD Biosciences). Apoptotic cells were defined as Annexin V-positive.

Western blot analysis. Following treatment, osteoblasts were extracted with RIPA lysis buffer for $30 \mathrm{~min}$ at $4^{\circ} \mathrm{C}$. The supernatants containing total protein were harvested and proteins were quantified using the bicinchoninic acid method. Samples with an average volume of $50 \mu \mathrm{g}$ were resolved using SDS-PAGE (12\% gel) and transferred onto polyvinylidene fluoride membranes at $60 \mathrm{~V}$ for $2 \mathrm{~h}$ at $4^{\circ} \mathrm{C}$. Membranes were then immediately soaked in blocking buffer [5\% blocking buffer ( 0.5 liter) containing $25 \mathrm{mg}$ bovine serum albumin in TBS buffer to final volume of 0.51 , maintained at $4^{\circ} \mathrm{C}$ ] for $2 \mathrm{~h}$ at room temperature. Subsequently, proteins were incubated with primary antibodies against GRP78 (cat. no. ab21685), GRP94 (cat. no. ab53075), ATF4 (cat. no. ab23760), ATF6a (cat. no. ab37149), XBP1 (cat. no. ab37152), phosphorylated (p-)eIF2 $\alpha$ (cat. no. ab4837), POSTN (cat. no. ab79946), caspase-3 (ab90437) and p-JNK (cat. no. ab124956). All primary antibodies were diluted at 1:5,000 and incubated overnight at $4^{\circ} \mathrm{C}$, followed by incubation with goat anti-rabbit peroxidase-conjugated secondary antibody $(1: 10,000$; cat. no. ab6721) for $2 \mathrm{~h}$ at room temperature. The DNR imaging system (DNR Bio-Imaging Systems, Ltd., Jerusalem, Israel) was used to visualize specific bands, and the optical density of each band was measured using ImageJ software (version 1.51; NIH, Bethesda, MD, USA). The expression ratio of the indicated target proteins to $\beta$-actin (cat. no. ab8226) was calculated and presented graphically. All antibodies were purchased from Abcam.

Reverse transcription-quantitative polymerase chain reaction (RT-qPCR) assays. Total RNA was extracted from the osteoblasts using the E.Z.N.A. ${ }^{\circledR}$ Total RNA Midi kit (Omega Bio-Tek, Inc., Norcross, GA, USA) according to manufacturer's protocol, and quantified spectrophotometrically at $260 \mathrm{~nm}$ with acceptable 260/280 ratios being defined as between 1.8 and 2.0. The RNA quality was also assessed using $1 \%$ agarose gel electrophoresis and staining with $1 \mu \mathrm{g} / \mathrm{ml}$ ethidium bromide. The RT-qPCR analysis was performed on a LightCycler ${ }^{\circledR} 480$ High-Resolution Melting Master (Roche Diagnostics, Indianapolis, IN, USA) using SYBR Premix Ex Taq $^{\text {TM }}$ II (Takara Biotechnology Co., Ltd., Dalian, China). The DNA polymerase, Takara Ex Taq ${ }^{\mathrm{TM}} \mathrm{HS}$, was also obtained from Takara Biotechnology Co., Ltd. Amplifications were performed in a total volume of $20 \mu 1$ [10.0 $\mu \mathrm{l}$ of $2 \mathrm{x}$ SYBR Premix Ex Taq II (Takara Biotechnology Co., Ltd.) $0.8 \mu \mathrm{l}$ forward primer, $0.8 \mu 1$ reverse primer, $2.0 \mu \mathrm{l}$ DNA template, $6.4 \mu \mathrm{l}$ double distilled $\mathrm{H}_{2} \mathrm{O}$ ], and cycled for 40 cycles following initial denaturation $\left(95^{\circ} \mathrm{C}\right.$ for $\left.30 \mathrm{sec}\right)$ with the following parameters: $95^{\circ} \mathrm{C}$ for $5 \mathrm{sec}$ and $60^{\circ} \mathrm{C}$ for $30 \mathrm{sec}$. Primer sequences are specified in Table I. $\beta$-actin (forward, TCCTCC CTGGAGAAGAGCTA and reverse, TCAGGAGGAGCA ATGATCTTG) were used as internal controls. Analysis of the melting curves supported the reliability of the results. The RT-qPCR data were calculated using the $2^{-\Delta \Delta \mathrm{Cq}}$ method (27) (Applied Biosystems; Thermo Fisher Scientific, Inc.). 
Table I. Forward primer and reverse primer of associated genes.

\begin{tabular}{ll} 
Gene & \multicolumn{1}{c}{ Primers } \\
\hline XBP1 & F: GCGCTGAGGAGGAAACTGAA \\
& R: GCGCTGTCTTAACTCCTGGT \\
ATF4 & F: GTCCCTCCAACAACAGCAAG \\
& R: ACTTTCTGGGAGATGGCCAA \\
ATF6 $\alpha$ & F: CTGTTACCAGCTACCACCCA \\
& R: GGAGCCAAAGAAGGTGTTGG \\
POSTN & F: GTGACAGAAGTGATCCACGGAG \\
& R: CTCTTGATCGCCTTCTAGACCC
\end{tabular}

XBP1, $\mathrm{X}$ box binding protein 1; ATF, activating transcription factor; POSTN, periostin; F, forward; R, reverse.

Statistical analysis. SPSS (version 20.0; IBM SPSS, Armonk, NY, USA) was used to complete data processing. An independent samples t-test or one-way analysis of variance, followed by the student Newman-Keuls test, was used to evaluate the differences between groups with various treatments. Results were expressed as mean \pm standard error of the mean. The $\mathrm{N}$-fold gene expression values in gene expression $\leq 0.5$ and $>2$ were considered to be significant, in accordance with the values obtained from the control genes. $\mathrm{P}>0.05$ was considered to indicate a statistically significant difference.

\section{Results}

Detection of apoptosis. Apoptosis of the osteoblasts was detected using Annexin V-FITC/PI staining. The number of early apoptotic cells was assessed according to the number of scatters in the different quadrants. The numbers of the early and late apoptotic cells were observed in each group. Results demonstrate that the quantity of early apoptotic cells in the Q4 (early apoptotic) region are significantly different between groups, for example, Fig. $1 \mathrm{~A}(0 \mathrm{mM} / 1$ melatonin, $24 \mathrm{~h})$ and Fig. 1B (2 mM/l melatonin, $24 \mathrm{~h})$ exhibit decrease levels of early apoptotic cells compared with Fig. 1C (4 mM/l melatonin, $24 \mathrm{~h}$ ). However, the number of late apoptotic cells in the Q2 region of Fig. 1B and D was increased compared with Fig. 1C. Following treatment with melatonin for $48 \mathrm{~h}$, the number of late apoptotic cells increased for all concentrations of melatonin, results also demonstrated that the total quantity of apoptotic cells was increased at $2 \mathrm{mM} / 1$ melatonin (Fig. 1E). Following comprehensive consideration, $4 \mathrm{mM}$ melatonin (dissolved in $0.2 \% \mathrm{DMSO}$ ) for $24 \mathrm{~h}$ was selected as the appropriate experimental condition for subsequent experiments as this group exhibited the greatest number of early apoptotic cells (Q4) and the least number of late apoptotic cells (Q2).

Occurrence of ERS. The occurrence of ERS was detected by assessing the expression of GRP78 and GRP94. It was previously indicated that the expression levels of these proteins are often increased significantly when ERS occurs (28). In the present study, the expression of these two proteins was observed and there were significant differences among the groups treated with different concentrations of melatonin for different durations (Fig. 2). The results showed that treatment with a certain concentration of melatonin for a certain length of time induced the occurrence of ERS in the hFOB 1.19 human osteoblastic cell line.

Signaling transduction pathway expression. Proteins associated with the signaling transduction pathways, including PERK, IRE1 and ATF6 $\alpha$, activated by UPR were also assessed. The protein and mRNA expression levels of p-eIF2 $\alpha$, ATF4, $\mathrm{X}$-box binding protein 1 (XBP1) and ATF6 $\alpha$ were measured using western blot and RT-qPCR analyses, and the results showed that the expression levels of p-eIF2 $\alpha$ and ATF4 were increased significantly among the groups (Fig. 3A and B). The increased expression levels of the above proteins indicated that melatonin induced apoptosis of the hFOB 1.19 human normal osteoblastic cells through the PERK-eIF2 $\alpha$-ATF4 pathway, but not through the IRE1 or ATF6 $\alpha$ pathways.

The expression of POSTN in the groups treated with different concentrations of melatonin for $24 \mathrm{~h}$ was assessed using western blot and RT-qPCR analyses. The results showed that the expression of POSTN was positively correlated with the concentration of melatonin (Fig. 4A and B), which indicated that, with the increased intensity of apoptosis, the upregulated expression of POSTN may be a mechanism underlying the anti-apoptotic effect in osteoblasts.

To determine the transduction pathways through which ERS mediate melatonin-induced apoptosis, the expression levels of CHOP and caspase- 3 were detected using western blot analysis. It was observed that $4 \mathrm{mM}$ melatonin significantly increased the expression levels of ATF4, p-eIF $2 \alpha, \mathrm{CHOP}$ and caspase-3 following treatment for $24 \mathrm{~h}$ (Fig. 5), compared with those in the control groups. The levels of p-JNK were also markedly increased (Fig. 5). Therefore, melatonin-induced apoptosis may activate the JNK pathway.

RT-qPCR analysis was performed to assess the mRNA level of POSTN following transfection with the POSTN overexpression plasmid or POSTN siRNA. The results showed that the transfections were efficient (Fig. 6).

Effect of POSTN on melatonin-induced apoptosis. Finally, either POSTN siRNA or control siRNA were transfected into osteoblasts using Lipofectamine ${ }^{\circledR} 2000$ according to the manufacturer's protocol. There were three control groups: Blank control, transfection reagent control and scramble siRNA control. A rescue experiment was also performed via transfection with the POSTN overexpression plasmid (Genechem Co., Ltd.). Western blot analysis was then performed to assess the protein levels of CHOP, ATF4, p-eIF2 $\alpha$, pro caspase-3, cleaved caspase-3 and POSTN. The results demonstrated that the levels of CHOP, ATF4, p-eIF $2 \alpha$ and cleaved caspase-3 in the group treated with melatonin in combination with POSTN siRNA were increased significantly, compared with those in the control groups. Following transfection with POSTN siRNA, the expression level of POSTN decreased significantly. The POSTN overexpression plasmid was then transfected in order to perform the rescue experiment. The results demonstrated that following transfection with the POSTN overexpression plasmid, the expression level of 

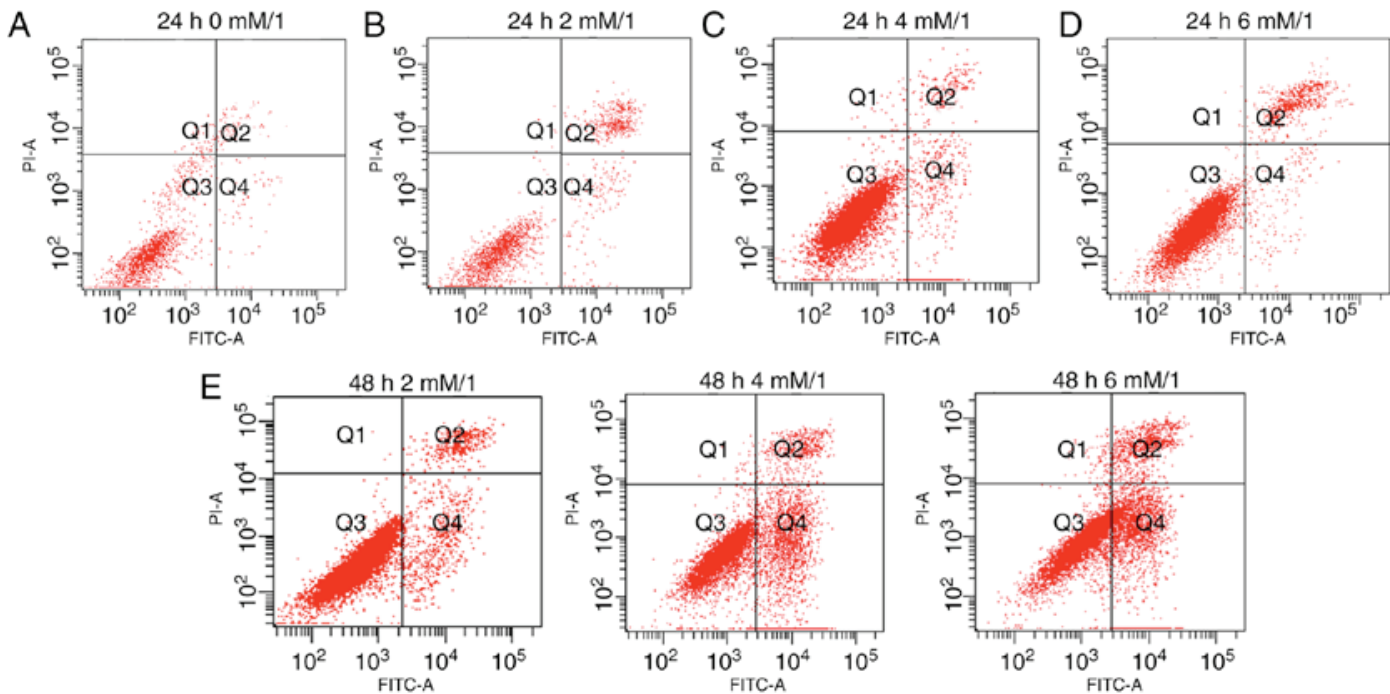

Figure 1. Effect of melatonin on the apoptosis in hFOB 1.19 human osteoblastic cells. The cells were treated with vehicle or melatonin (2,4 and $6 \mathrm{mM})$ alone for 24 and 48 h. PI, propidium iodide; FITC, fluorescein isothiocyanate.

\begin{tabular}{|c|c|c|c|c|c|c|c|c|c|c|}
\hline Melatonin & \multirow{2}{*}{ Control } & \multicolumn{3}{|c|}{$2 \mathrm{mM} / 1$} & \multicolumn{3}{|c|}{$4 \mathrm{mM} / 1$} & \multicolumn{3}{|c|}{$6 \mathrm{mM} / 1$} \\
\hline Genes & & $4 \mathrm{~h}$ & $24 \mathrm{~h}$ & $48 \mathrm{~h}$ & $4 \mathrm{~h}$ & $24 \mathrm{~h}$ & $48 \mathrm{~h}$ & $4 \mathrm{~h}$ & $24 \mathrm{~h}$ & $48 \mathrm{~h}$ \\
\hline GRP78 BIP & - & - & & $=$ & - & 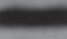 & $=$ & $=$ & $\rightarrow$ & $\Rightarrow$ \\
\hline GRP94 & - & - & $\longrightarrow$ & $=$ & $\rightarrow$ & 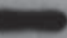 & 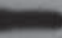 & - & $=$ & $=$ \\
\hline$\beta$-actin & 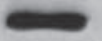 & $\infty$ & 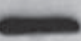 & 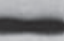 & 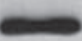 & $=$ & $=$ & 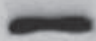 & $=$ & 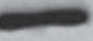 \\
\hline
\end{tabular}
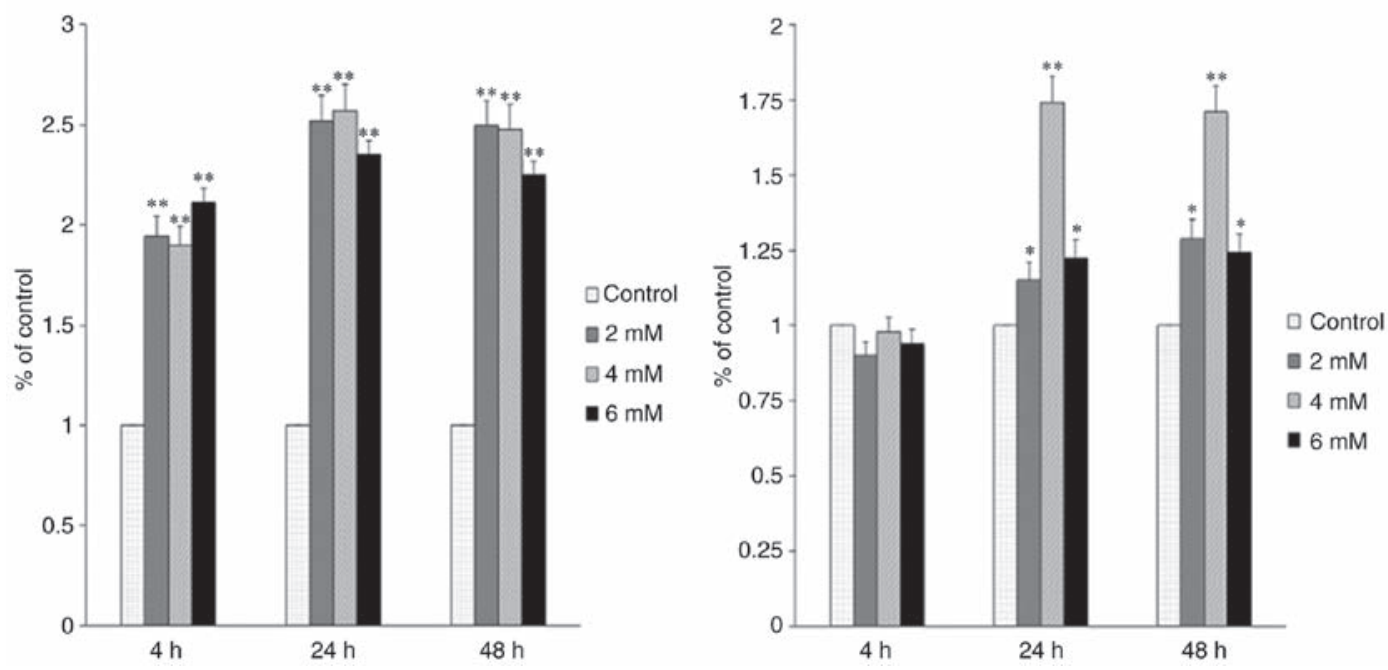

Figure 2. Effect of melatonin on the expression of GRP78 and GRP94 in hFOB 1.19 human osteoblastic cells. The cells were treated with vehicle or melatonin $(2,4$ and $6 \mathrm{mM})$ alone for 4, 24 and $48 \mathrm{~h}$. Each bar represents the mean \pm standard error of the mean of three independent experiments. "P<0.05 and ${ }^{* * *} \mathrm{P}<0.01$ vs. control groups that did not receive any treatment. GRP, glucose-regulated protein; BIP, binding immunoglobulin protein.

POSTN was increased to a level similar to what was observed in the $4 \mathrm{mM}$ melatonin-treated group compared with the control group (Fig. 7). Collectively, it was deduced that POSTN inhibited melatonin-induced cell apoptosis by suppressing the PERK pathway.

\section{Discussion}

Melatonin may possess numerous functions in ageing, tumor growth, reproduction and skeletal physiology, and has various biological effects in human/animal cells (29-32). Several 

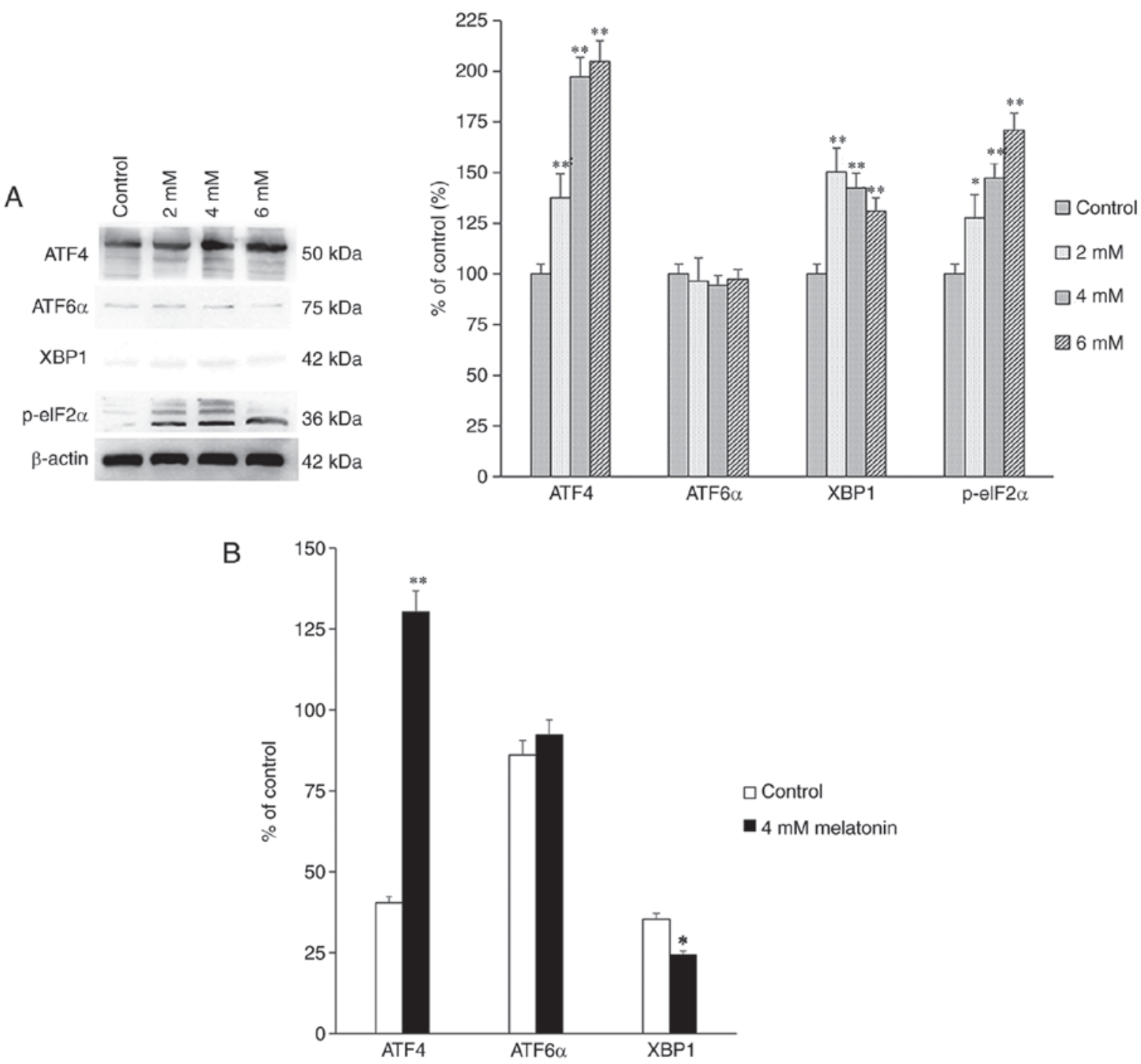

Figure 3. Effect of melatonin $(2,4$ and $6 \mathrm{mM})$ alone on the protein and mRNA expression levels of p-eIF2 $\alpha$, ATF4, XBP1 and ATF6 in the hFOB 1.19 human osteoblastic cell line for $24 \mathrm{~h}$. (A) mRNA expression levels. (B) Protein expression levels. Each bar represents the mean \pm standard error of the mean of three independent experiments. ${ }^{*} \mathrm{P}<0.05$ and $^{* *} \mathrm{P}<0.01$ vs. control cells. p-eIF $2 \alpha$, phosphorylated eukaryotic initiation factor $2 \alpha$; ATF, activating transcription factor; XBP1, X-box binding protein 1.

previous studies have demonstrated that melatonin is vital in promoting bone formation by strengthening osteoblast proliferation, differentiation and matrix formation (33-36). Previous studies have confirmed that melatonin has a concentrationdependent dual effect on osteoblast proliferation $(35,36)$; however, whether melatonin can affect cell apoptosis remains unclear. In the present study, it was initially demonstrated that melatonin induced cell apoptosis in the hFOB 1.19 human osteoblastic cell line. When the duration of action was prolonged to $24 \mathrm{~h}$, apoptosis occurred in addition to the ERS.

The ER is a site for processing proteins and storing calcium ions $(37,38)$. Cell dysfunction caused by alterations in the cellular environment may lead to ERS. ERS is a recognized as a stress response of subcellular organelles, which can activate three signal transduction pathways to relieve stress (10-12) and maintain cell homeostasis. Due to results presented in Fig. 2, it may be assumed that when the induction of ERS is enhanced, and when the duration of induction is prolonged (which overloads the anti-stress capacity of ERS), unfolded proteins continue to form and no longer degrade, and apoptosis may occur. Hamamura and Yokota (39) demonstrated that different intensities of ERS produced bidirectional regulation in mouse osteoblasts. A low level of ERS had protective effects on osteoblasts by increasing the expression of Runt-related transcription factor 2 (Runx2) and other bone morphogenetic factors, which promotes bone formation and remodeling. Contrastingly, increased levels of ERS increased the expression of ATF4, which subsequently increased the expression of downstream CHOP transcription factors. Furthermore, the increased expression of CHOP may cause apoptosis (40). Yu and Hong (41) also identified that Runx 2 promotes bone formation, inhibited the transformation of LC3II and inhibited autophagy.

ERS occurred following treatment with $4 \mathrm{mM}$ melatonin for $24 \mathrm{~h}$. It was demonstrated that melatonin induced ERS in the hFOB 1.19 human osteoblastic cell line. By assessing the expression of GRP78, it was demonstrated that melatonin induced ERS in the human hFOB 1.19 osteoblastic cells. GRP78 binds tightly to the three transmembrane signal proteins, PERK, IRE1 $\alpha$ and ATF6 $\alpha$, which are inactive under 
A

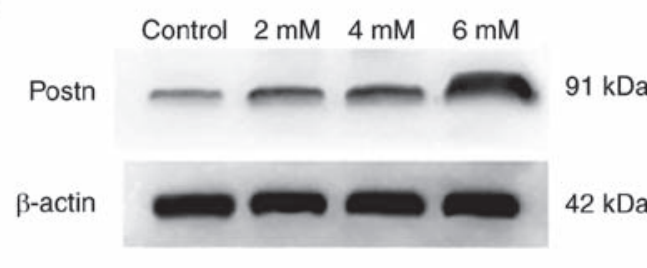

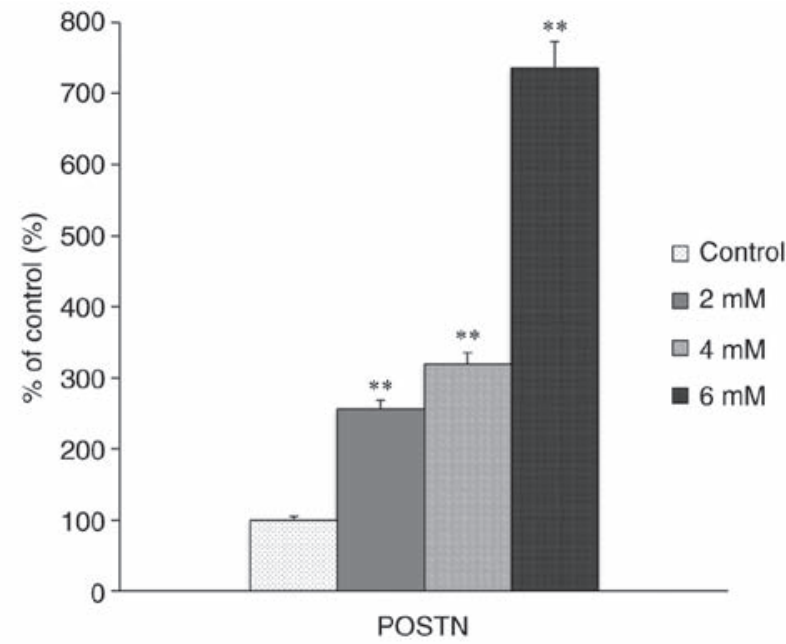

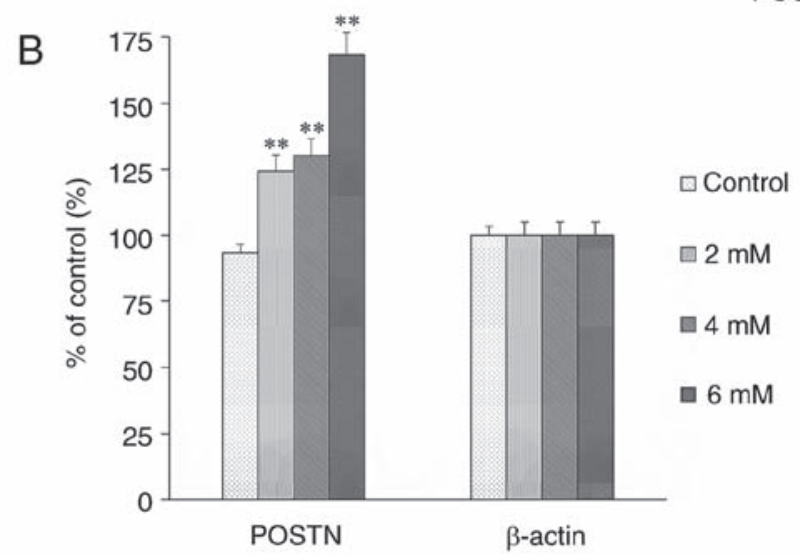

Figure 4. Effect of melatonin (2, 4 and $6 \mathrm{mM})$ on the protein and mRNA expression levels of POSTN in hFOB 1.19 human osteoblastic cells for $24 \mathrm{~h}$. (A) Protein expression levels. (B) mRNA expression levels. Each bar represents the mean \pm standard error of the mean of three independent experiments. ${ }^{* *} \mathrm{P}<0.01$ vs. control cells. POSTN, periostin.

normal circumstances $(42,43)$; when ERS occurs, GRP78 separates from one or all of the specified proteins, leading to an increase in protein expression causing a series of signaling cascades. Once these three proteins are activated, they may induce apoptosis by activating or inhibiting various factors.

Melatonin is able to clear reactive oxygen species and activate antioxidant systems (44). However, studies have demonstrated that increased concentrations of melatonin have pro-oxidant effects (43) and that oxidative stress contributes to activation of the UPR, which may lead to ERS (45). These two opposing effects may be independent of cell types (43), namely, a pro-apoptotic effect in cancer cells vs. an anti-apoptotic effect in normal cells under normal conditions (46). The results of the present study do not conform to the above conclusions. Melatonin used at high concentrations $(4 \mathrm{mM})$ induced ERS and induced apoptosis in the hFOB 1.19 human osteoblastic cell line, which complicates the biological effects of melatonin.

According to the different concentrations of melatonin and durations of action, the present study assessed apoptosis, ERS-associated proteins and other indicators. The results revealed that ERS had a protective effect. Results presented in Fig. 1 indicated that, following treatment with $4 \mathrm{mM}$ melatonin for $24 \mathrm{~h}$, the intensity of melatonin-induced apoptosis reached its peak (Figs. 1 and 2). Consistent with the duration of action of melatonin, ERS no longer protected osteoblasts but instead induced apoptosis, and the results of the 24 and $48 \mathrm{~h}$ groups also exhibited an apoptotic response (Fig. 1). Following comprehensive consideration, $4 \mathrm{mM}$ melatonin for $24 \mathrm{~h}$ was selected as the appropriate experimental conditions for subsequent experiments.

The present study assessed the expression levels of pro caspase-3 and cleaved caspase-3 as markers of apoptosis. The expression levels of ATF4, CHOP and cleaved caspase-3 increased (Figs. 3 and 5B) indicated that the melatonin concentration and duration of action may have surpassed the threshold under which the UPR was able to maintain cell homeostasis, and may have led to subsequent cell apoptosis. The three transmembrane proteins mentioned above separate from binding immunoglobulin protein and are involved in three signal transduction pathways $(16,17)$, namely, the PERK-eIF $2 \alpha-A T F 4$ pathway, the IRE1 $\alpha$-XBP1 pathway and the ATF6 $\alpha$ pathway. eIF $2 \alpha$ is immediately phosphorylated by PERK in response to ERS, which prevents global protein synthesis, but selectively induces the translation of ATF4 (47). CHOP is an important downstream target of ATF4, and the presence of CHOP is an essential factor for the apoptotic response to ERS (48). The present study demonstrated that, when apoptosis occurs, the levels of p-eIF2 $\alpha$ and ATF4 increased sequentially, whereas no significant changes were observed in the expression levels of XBP1 and ATF6 $\alpha$ (Fig. 3A). These results indicated that melatonin-induced ERS led to the phosphorylation of eIF2 $\alpha$ and activated the translation of ATF4, finally causing the 

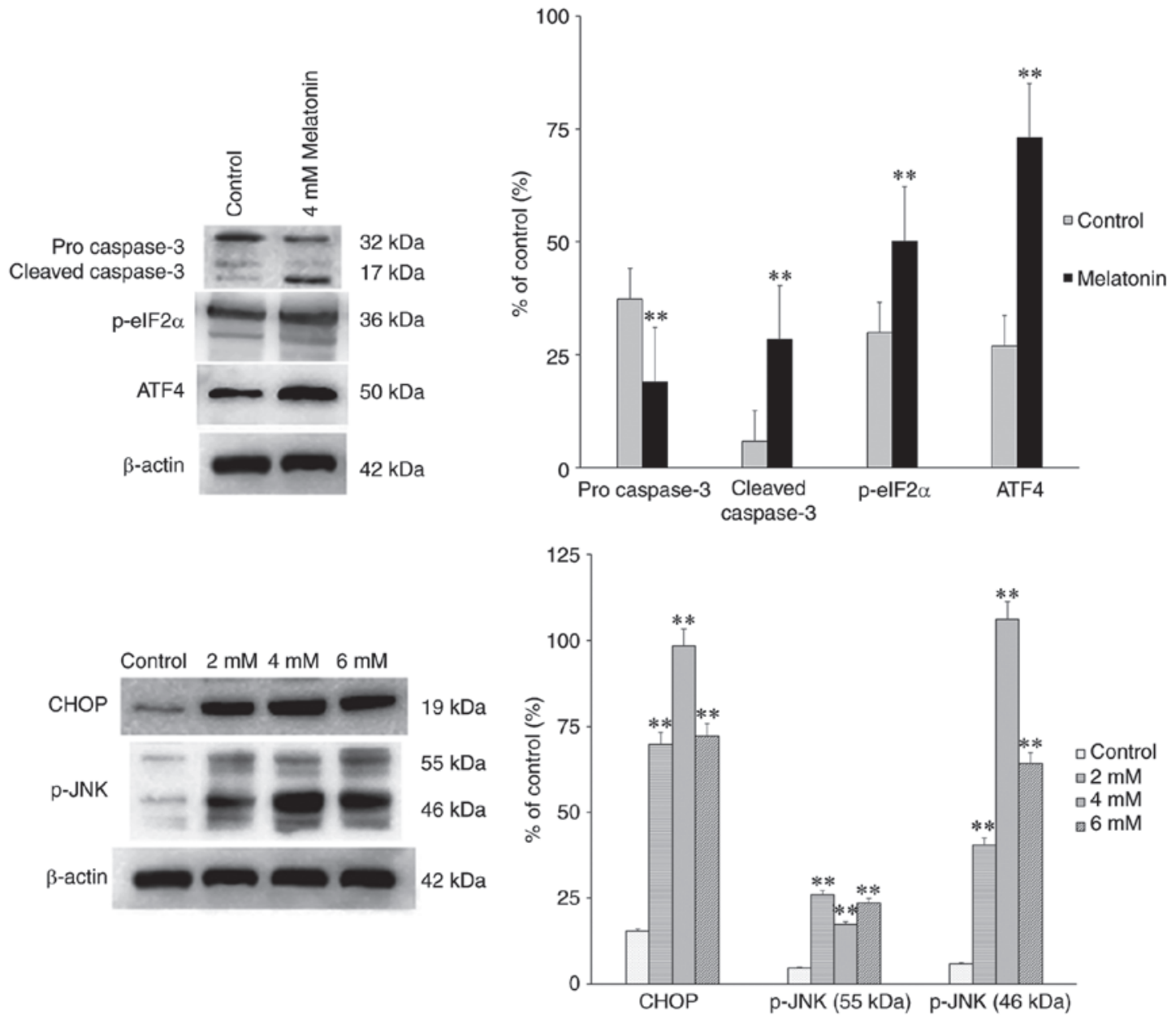

Figure 5. Effect of melatonin $(2,4$ and $6 \mathrm{mM})$ on the protein expression levels of pro caspase-3, cleaved-caspase-3, p-eIF2 $\alpha$, CHOP and p-JNK in hFOB 1.19 human osteoblastic cells for $24 \mathrm{~h}$. Each bar represents the mean \pm standard error of the mean of three independent experiments. ** $\mathrm{P}<0.01$ vs. control cells. POSTN, periostin; p-eIF2 $\alpha$, phosphorylated eukaryotic initiation factor $2 \alpha$; ATF4, activating transcription factor 4; CHOP, CCAAT/enhancer binding protein homologous protein; JNK, c-Jun N-terminal kinase; p-, phosphorylated.

activation of CHOP. Previous studies have demonstrated that melatonin can increase the levels of CHOP and decrease the Bcl-2/Bcl-2-associated $\mathrm{X}$ protein (Bax) ratio in human hepatoma cells (5). Furthermore, the activation of CHOP leads to changes in gene expression, which favors apoptosis by decreasing the expression of Bcl-2 and increasing the expression of Bax $(21,49)$. Following ERS, three pathways are involved in inducing apoptosis, namely, the mitochondria-mediated pathway (10), death receptor pathway and the ER pathway (caspase pathway). In the present study, the expression of p-eIF2 $\alpha$, ATF4 and cleaved-caspase-3 increased (Fig. 5), which demonstrated that the melatonin-induced apoptosis was associated with the ER pathway and the eIF $\alpha$-ATF4 pathway. The JNKs are one of the three well-defined subgroups of mitogen-activated protein kinases (MAPKs); the other two subgroups comprise the ERKs and p38 MAPKs. All three of the above-mentioned subgroups can be activated by a cascade of phosphorylation events, and are involved in gene expression, differentiation, cell survival and cell death (50). In the present study, the level of p-JNK was significantly increased (Fig. 5), which indicated that the JNK subgroup of MAPKs was significantly upregulated in the melatonin-treated groups, compared with that in the control group. This suggested that the JNK pathways may be associated with apoptosis of the hFOB 1.19

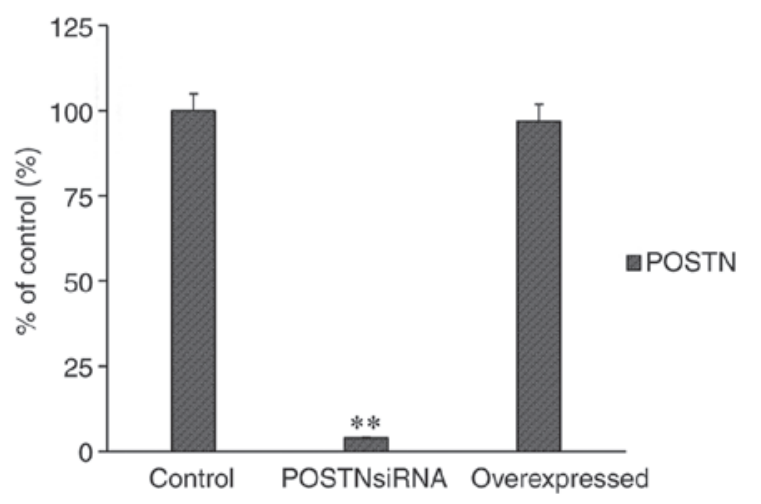

Figure 6. Effect of POSTN siRNA on the mRNA level of POSTN in hFOB 1.19 human osteoblastic cells for $24 \mathrm{~h}$. Each bar represents the mean \pm standard error of the mean of three independent experiments. ${ }^{* *} \mathrm{P}<0.01 \mathrm{vs}$. control cells. siRNA, small interfering RNA; POSTN, periostin.

human osteoblastic cell line and that melatonin takes effect through this pathway. CHOP is involved in another major pathway through which apoptotic responses to ERS occur, namely, the ER pathway (51). Previous studies have indicated that CHOP may be involved in the death receptor pathway, particularly the death receptor 5 pathway $(8,9)$. 

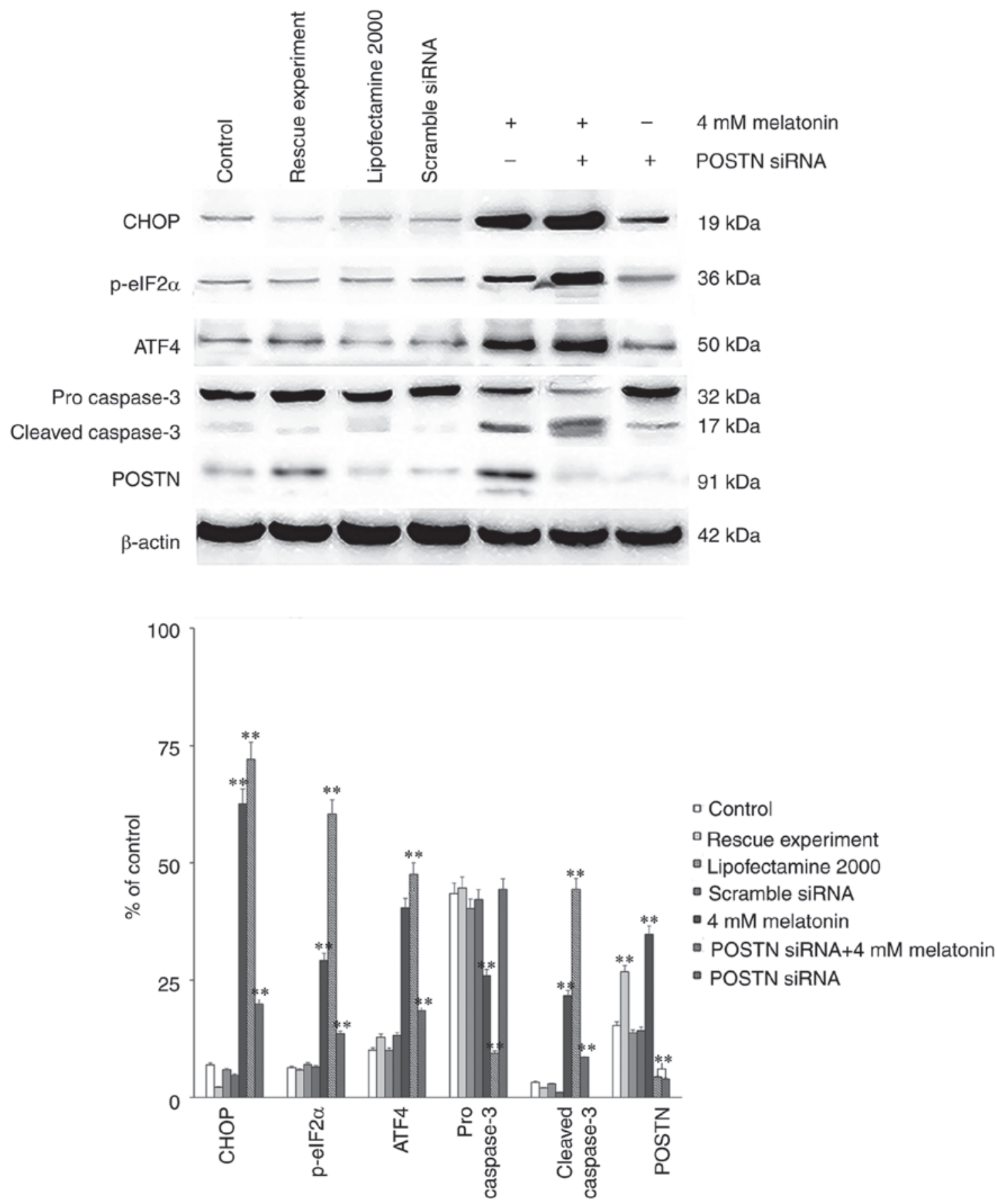

Figure 7. Protein levels from control groups and rescue experiment of POSTN siRNA, and the effect of melatonin (4 mM) alone or in combination with the POSTN-siRNA on the protein expression levels of CHOP, p-eIF2 $\alpha$, ATF4, pro caspase-3, cleaved caspase-3 and POSTN in hFOB 1.19 human osteoblastic cells. Each bar represents the mean \pm standard error of the mean of three independent experiments. ${ }^{* * *} \mathrm{P}<0.01$ vs. melatonin-treated cells. p-eIF2 $\alpha$, phosphorylated eukaryotic initiation factor $2 \alpha$; CHOP, CCAAT/enhancer binding protein homologous protein; ATF4, activating transcription factor 4; POSTN, periostin; siRNA, small interfering RNA.

POSTN is an extracellular matrix protein, which is secreted by osteoblasts (50). This protein is expressed in bone tissues, although its function remains unclear. In several types of cancer, POSTN can activate the Akt and focal adhesion kinase-mediated signaling pathways, subsequently leading to cell invasion, angiogenesis, metastasis and epithelial-mesenchymal transition (52). POSTN is involved in several cancer biological processes, including proliferation $(53,54)$, migration $(55)$, invasion/metastasis $(56,57)$ and angiogenesis $(57,58)$. Studies have demonstrated that the upregulation of POSTN is able to prevent cell apoptosis in different cell types (59-61). In the present study, it was indicated that the inhibition of POSTN increased the intensity of melatonin-induced cell apoptosis in the hFOB 1.19 human osteoblastic cell line. The present study assessed the apoptosis and ERS-associated proteins CHOP, ATF4, p-eIF2 $\alpha$, p-JNK, procaspase- 3 and cleaved caspase- 3 in the control group, compared wit the POSTN-inhibited group, and the two groups were treated with identical concentrations of melatonin for identical durations. The results demonstrated that in the POSTN-inhibited 
group, expression of the above-mentioned proteins increased following treatment with $4 \mathrm{mM}$ melatonin for $24 \mathrm{~h}$, which suggested that when the protein level of POSTN decreased, the intensity of melatonin-induced apoptosis increased. These two parameters were negatively associated. These results indicated that POSTN may have a protective effect in melatonin-induced apoptosis of the hFOB 1.19 human osteoblastic cell line.

In the present study, the POSTN siRNA was transfected into the hFOB 1.19 human osteoblastic cell line and the efficiency of transfection was assessed using RT-qPCR analysis (Fig. 6). According to the results of the western blot analysis, the effect of $4 \mathrm{mM}$ melatonin alone or in combination with POSTN siRNA demonstrated significant differences. The expression levels of the ERS and apoptosis-related proteins peaked in the melatonin + POSTN siRNA group, and the expression levels were lowest in the group treated with POSTN siRNA alone. These results indicated that POSTN may mediate this process by suppressing the expression levels of p-eIF2 $\alpha$ and ATF4 (Fig. 7). The expression of POSTN has been demonstrated to be inducible by stress or pressure overloading (62). In the present study, melatonin was used to investigate the effects of ERS and apoptosis on the expression of POSTN in human osteoblast cells. Following the induction of ERS and apoptosis, the expression of POSTN was detected and the results demonstrated that, with the increasing concentrations and durations of melatonin treatment, the expression of POSTN exhibited concentration- and time-dependent increases (Fig. 4A).

In conclusion, melatonin induced cell apoptosis by activating the PERK-p-eIF2 $\alpha$-ATF signal transduction pathway, and ERS mediated this process by triggering the cascade reactions of CHOP, caspase-3 and p-JNK. The upregulated expression of POSTN had a protective effect against apoptosis of the hFOB 1.19 human osteoblastic cell line. The expression level of POSTN in this process was positively associated with the concentration of melatonin, which suggested that the existence of POSTN may be a protective mechanism in this biological process. POSTN inhibited apoptosis by affecting the expression levels of the pathway-related proteins and protecting the hFOB 1.19 human osteoblastic cell line. Previous studies have confirmed that POSTN had a stimulatory effect in the proliferation of hFOB 1.19 human osteoblastic cells, which was in accordance with the conclusion of the present study. In addition, the preferential localisation of these cells to the periosteum, which is highly sensitive to mechanical stimulation, suggested that POSTN and transforming growth factor $\beta$-induced protein may be important to the maintenance of bone strength. Therefore, the development of specific and sensitive assays for serum measurements of these proteins is critical for investigating their potential as biomarkers of adaptive bone remodeling.

\section{Acknowledgements}

The present study was supported by the National Natural Science Foundation of China (grant no. 81472044). The authors would like to thank Dr M. Subramaniam of the Department of Biochemistry and Molecular Biology, Mayo Clinic, Rochester MN, USA for providing osteoblasts.

\section{References}

1. Thillard MJ: Deformations de la colonne vertebrale consecutives à l'épiphysectomie chez le poussin. Extrait $\mathrm{C} R$ Assoc Anat 46: 22-26, 1959 (In French).

2. Liu L, Zhu Y, Xu Y and Reiter RJ: Melatonin delays cell proliferation by inducing $\mathrm{G} 1$ and $\mathrm{G} 2 / \mathrm{M}$ phase arrest in a human osteoblastic cell line hFOB 1.19. J Pineal Res 50: 222-231, 2011.

3. Liu L, Zhu Y, Xu Y and Reiter RJ: Prevention of ERK activation involves melatonin-induced $\mathrm{G}(1)$ and $\mathrm{G}(2) / \mathrm{M}$ phase arrest in the human osteoblastic cell line hFOB 1.19. J Pineal Res 53: 60-66, 2012.

4. Moreira AJ, Ordoñez R, Cerski CT, Picada JN, García-Palomo A, Marroni NP, Mauriz JL and González-Gallego J: Melatonin activates endoplasmic reticulum stress and apoptosis in rats with diethylnitrosamine-induced hepatocarcinogenesis. PLoS One 10: e0144517. 2015

5. Zha L, Fan L, Sun G, Wang H, Ma T, Zhong F and Wei W: Melatonin sensitizes human hepatoma cells to endoplasmic reticulum stress-induced apoptosis. J Pineal Res 52: 322-331, 2012.

6. Wongprayoon P and Govitrapong P: Melatonin protects sh-sy5y neuronal cells against methamphetamine-induced endoplasmic reticulum stress and apoptotic cell death. Neurotox Res 31: 1-10, 2017.

7. Espino J, Bejarano I, Paredes SD, Barriga C, Reiter RJ, Pariente JA and Rodríguez AB: Melatonin is able to delay endoplasmic reticulum stress-induced apoptosis in leukocytes from elderly humans. AGE (Dordr) 33: 497-507, 2011.

8. Yi L, Zongyuan Y, Cheng G, Lingyun Z, Guilian Y and Wei G: Quercetin enhances apoptotic effect of tumor necrosis factor-related apoptosis-inducing ligand (TRAIL) in ovarian cancer cells through reactive oxygen species (ROS) mediated CCAAT enhancer-binding protein homologous protein (CHOP)-death receptor 5 pathway. Cancer Sci 105: 520-527, 2014.

9. He L, Jang JH, Choi HG, Lee SM, Nan MH, Jeong SJ, Dong Z, Kwon YT, Lee KS, Lee KW, et al: Oligomycin a enhances apoptotic effect of TRAIL through CHOP-mediated death receptor 5 expression. Mol Carcinog 52: 85-93, 2013.

10. Xiong SB, Mu TY, Wang GW and Jiang X: Mitochondria-mediated apoptosis in ma mMals. Protein Cell 5: 737-749, 2014.

11. Xu C, Bailly-Maitre B and Reed JC: Endoplasmic reticulum stress: Cell life and death decisions. J Clin Invest 115: 2656-2664, 2005.

12. Faitova J, Krekac D, Hrstka R and Vojtesek B: Endoplasmic reticulum stress and apoptosis. Cell Mol Biol Lett 11: 488-505, 2006.

13. Phal HL: Signal transduction from the endoplasmic reticulum to the cell nucleus. Physiol Rev 79: 683-701, 1999.

14. Espenshade PJ: SREBPs: Sterol-regulated transcription factors. J Cell Sci 15: 973-976, 2006.

15. Davenport EL, Morgan GJ and Davies FE: Untangling the unfolded protein response. Cell Cycle 7: 865-869, 2008.

16. Malhotra JD and Kaufman RJ: The endoplasmic reticulum and the unfolded protein response. Semin Cell DevBiol 18: 716-731, 2007.

17. Gupta S, Deepti A, Deegan S, Lisbona F, Hetz C and Samali A: HSP72 protects cells from ER stress-induced apoptosis via enhancement of IRE1alpha-XBP1 signaling through a physical interaction. PLoS Biol 8: e1000410, 2010.

18. Long ZS: Expression and significance of CHOP related ERS after acute spinal cord injury in rats. Chin J Spine Spinal Cord 19: 458-463, 2009 (In Chinese).

19. Szegezdi E, Duffy A, O'Mahoney ME, Logue SE, Mylotte LA, O'brien T and Samali A: ER stress contributes to ischemia-induced cardiomyocyte apoptosis. Biochem Biophys Res Commun 349: 1406-1411, 2006.

20. Takeda K, Shimozono R, Noguchi T, Umeda T, Morimoto Y, Naguro I, Tobiume K, Saitoh M, Matsuzawa A and Ichijo H: Apoptosis signal-regulation kinase (ASK) 2 functions as a mitogen-activated protein kinase in a heteromeric complex with ASK1. J Biol Chem 282: 7522-7531, 2007.

21. Li F, Guo Y, Sun S, Jiang X, Tang B, Wang Q and Wang L: Free cholesterol-induced macrophage apoptosis is mediated by inositol-requiring enzyme 1 alpha-regulated activation of Jun N-terminal kinase. Acta Biochim Biophys Sin Shanghai 40: 226-234, 2008 
22. Matsuzawa A, Saegusa K, Noguchi T, Sadamitsu C, Nishitoh H, Nagai S, Koyasu S, Matsumoto K, Takeda K and Ichijo H: Ros-dependent activation of the TRAF6-ASK1-p38 pathway is selectively required for TLR4-mediated innate immunity. Nat Immunol 6: 587-592, 2005.

23. Hoersch S and Andrade-Navarro MA: Periostin shows increased evolutionary plasticity in its alternatively spliced region. BMC Evol Biol 10: 30, 2010.

24. Morra L and Moch H: Periostin expression and epithelial-mesenchymal transition in cancer: A review and an update. Virchows Arch 459: 465-475, 2011.

25. Merle B, Bouet G, Rousseau JC, Bertholon C and Garnero P: Periostin and transforming growth factor $\beta$-induced protein (TGF $\beta I$ Ip) are both expressed by osteoblasts and osteoclasts. Cell Biol Int 38: 398-404, 2014.

26. Subramaniam M, Jalal SM, Rickard DJ, Harris SA, Bolander ME and Spelsberg TC: Further characterization of human fetal osteoblastic hFOB 1.19 and hFOB/ER alpha cells: Bone formation in vivo and karyotype analysis using multicolor fluorescent in situ hybridization. J Cell Biochem 87: 9-15, 2002

27. Livak KJ and Schmittgen TD: Analysis of relative gene expression data using real-time quantitative PCR and the 2(-Delta Delta C(T)) method. Methods 25: 402-408, 2001.

28. Pizarro JG, Yeste-Velasco M, Esparza JL, Verdaguer E, Pallàs M, Camins A and Folch J: The antiproliferative activity of melatonin in B65 rat dopaminergic neuroblastoma cells is related to the downregulation of cell cycle-related genes. J Pineal Res 45: 8-16, 2008.

29. Reiter RJ, Tan DX and Fuentes-Broto L: Melatonin: A multi-tasking molecule. Prog Brain Res 181: 127-151, 2010.

30. Akbarzadeh M, Rahbarghazi R, Nabat E, Movassaghpour AA, Shanehbandi D, Faramarzian Azimi Maragheh B, Matluobi D, Barazvan B, Kazemi M, Samadi N and Nouri M: The impact of different extracellular matrices on melatonin effect in proliferation and stemness properties of ovarian cancer cells. Biomed Pharmacother 87: 288-295, 2017.

31. Bavithra S, Selvakumar K, Sundareswaran L and Arunakaran J: Neuroprotective effect of melatonin against pcbs induced behavioural, molecular and histological changes in cerebral cortex of adult male wistar rats. Neurochem Res 42: 428-438, 2017.

32. Khan S, Adhikari JS, Rizvi MA and Chaudhury NK: Melatonin attenuates 60 Co $\gamma$-ray-induced hematopoietic, immunological and gastrointestinal injuries in C57BL/6 male mice. Environ Toxicol 32: 501-518, 2017.

33. Satomura K, Tobiume S, Tokuyama R, Yamasaki Y, Kudoh K Maeda E and Nagayama M: Melatonin at pharmacological doses enhances human osteoblastic differentiation in vitro and promotes mouse cortical bone formation in vivo. J Pineal Res 42 231-239, 2007

34. Man GC, Wang WW, Yeung BH, Lee SK, Ng BK, Hung WY, Wong JH, Ng TB, Qiu Y and Cheng JC: Abnormal proliferation and differentiation of osteoblasts from girls with adolescent idiopathic scoliosis to melatonin. J Pineal Res 49: 69-77, 2010.

35. Nakade O, Koyama H, Ariji H, Yajima A and Kaku T: Melatonin stimulates proliferation and type I collagen synthesis in human bone cells in vitro. J Pineal Res 27: 106-110, 1999.

36. Sanchez-Hidalgo M, Lu Z, Tan DX, Maldonado MD, Reiter RJ and Gregerman RI: Melatonin inhibits fatty acid-induced triglyceride accumulation in ROS17/2.8 cells: Implications for osteoblast differentiation and osteoporosis. Am J Physiol Regul Integr Comp Physiol 292: R2208-R2215, 2007.

37. Anelli T and Sitia R: Protein quality control in the early secretory pathway. EMBO J 27: 315-327, 2008.

38. Pizzo P and Pozzan T: Mitochondria-endoplasmic reticulum choreography: Structure and signaling dynamics. Trends Cell Biol 17: 511-517, 2007.

39. Hamamura $\mathrm{K}$ and Yokota $\mathrm{H}$ : Stress to endoplasmic reticulum of mouse osteoblasts induces apoptosis and transcriptional activation for bone remodeling. FEBS Lett 581: 1769-1774, 2007.

40. Wysokinski D, Pawlowska E and Blasiak J: RUNX2: A master bone growth regulator that may be involved in the DNA damage response. DNA Cell Biol 34: 305-315, 2015.

41. Yu SH and Hong A: Runx 2 promotes osteogenic differentiating $\mathrm{C} 2 \mathrm{C} 12$ cells through inhibiting macroautophagy. Chin J Pathophysiol 29: 481-487, 2013 (In Chinese).
42. Ron D and Walter P: Signal integration in the endoplasmic reticulum unfolded protein response. Nat Rev Mol Cell Biol 8: 519-529, 2007.

43. Fernández A, Ordóñez R, Reiter RJ, González-Gallego J and Mauriz JL: Melatonin and endoplasmic reticulum stress: Relation to autophagy and apoptosis. J Pineal Res 59: 292-307, 2015.

44. Zhang HM and Zhang Y: Melatonin: A well-documented antioxidant with conditional pro-oxidant actions. J Pineal Res 57: 131-146, 2014.

45. Brown MK and Naidoo N: The UPR and the anti-oxidant response: Relevance to sleep and sleep loss. Mol Neurobiol 42 103-113, 2010.

46. Bizzarri M, Proietti S, Cucina A and Reiter RJ: Molecular mechanisms of the pro-apoptotic actions of melatonin in cancer: A review. Expert Opin Ther Targets 17: 1483-1496, 2013.

47. Tabas I and Ron D: Integrating the mechanisms of apoptosis induced by endoplasmic reticulum stress. Nat Cell Biol 13: 184-190, 2011.

48. Li Y, Guo Y, Tang J, Jiang J and Chen Z: New insights into the roles of CHOP-induced apoptosis in ER stress. Acta Biochim Biophys Sin 46: 629-640, 2014.

49. Fu HY, Okada K, Liao Y, Tsukamoto O, Isomura T, Asai M, Sawada T, Okuda K, Asano Y, Sanada S, et al: Ablation of C/EBP homologous protein attenuates endoplasmic reticulum-mediated apoptosis and cardiac dysfunction induced by pressure overload. Circulation 122: 361-369, 2010.

50. Hoersch S and Andrade-Navarro MA: Periostin shows increased evolutionary plasticity in its alternatively spliced region. BMC Evol Biol 10: 30, 2010

51. Lai E, Teodoro $\mathrm{T}$ and Volchuk A: Endoplasmic reticulum stress: Signaling the unfolded protein response. Physiology (Bethesda) 22: 193-201, 2007.

52. Morra L and Moch H: Periostin expression and epithelial-mesenchymal transition in cancer: A review and an update. Virchows Arch 459: 465-475, 2011.

53. Erkan M,Kleeff J, Gorbachevski A, Reiser C, Mitkus T, Esposito I, Giese T, Büchler MW, Giese NA and Friess H: Periostin creates a tumor-supportive microenvironment in the pancreas by sustaining fibrogenic stellate cell activity. Gastroenterology 132: $1447-1464,2007$

54. Tai IT, Dai M and Chen LB: Periostin induction in tumor cell line explants and inhibition of in vitro cell growth by anti-periostin antibodies. Carcinogenesis 26: 908-915, 2005.

55. Gillan L, Matei D, Fishman DA, Gerbin CS, Karlan BY and Chang DD: Periostin secreted by epithelial ovarian carcinoma is a ligand for alpha(V)beta(3) and alpha(V)beta(5) integrins and promotes cell motility. Cancer Res 62: 5358-5364, 2002.

56. Kudo Y, Ogawa I, Kitajima S, Kitagawa M, Kawai H, Gaffney PM, Miyauchi M and Takata T: Periostin promotes invasion and anchorage-independent growth in the metastatic process of head and neck cancer. Cancer Res 66: 6928-6935, 2006.

57. Siriwardena BS,Kudo Y,OgawaI,Kitagawa M,Kitajima S,HatanoH, Tilakaratne WM, Miyauchi M and Takata T: Periostin is frequently overexpressed and enhances invasion and angiogenesis in oral cancer. Br J Cancer 95: 1396-1403, 2006.

58. Shao R, Bao S, Bai X, Blanchette C, Anderson RM, Dang T, Gishizky ML, Marks JR and Wang XF: Acquired expression of periostin by human breast cancers promotes tumor angiogenesis through up-regulation of vascular endothelial growth factor receptor 2 expression. Mol Cell Biol 24: 3992-4003, 2004.

59. Li B, Wang L and Chi B: Upregulation of periostin prevents p53-mediated apoptosis in SGC-7901 gastric cancer cells. Mol Biol Rep 40: 1677-1683, 2013.

60. Aukkarasongsup P, Haruyama N, Matsumoto T, Shiga M and Moriyama K: Periostin inhibits hypoxia-induced apoptosis in human periodontal ligament cells via TGF- $\beta$ signaling. Biochem Biophys Res Commun 441: 126-132, 2013.

61. Luo JH, Zhou J and Gao Y: Correlation between periostin and SNCG and esophageal cancer invasion, infiltration and apoptosis. Asian Pac J Trop Med 6: 516-519, 2013.

62. Stansfield WE, Andersen NM, Tang RH and Selzman CH: Periostin is a novel factor in cardiac remodeling after experimental and clinical unloading of the failing heart. Ann Thorac Surg 88: 1916-1921, 2009. 